\title{
Comparison of Cesarean Sections Performed in the Second Stage of Labor and Vacuum-assisted Vaginal Delivery
}

\author{
(D) ilkbal Temel Yüksel, (1) Berna Aslan Çetin, (1) Gökalp Şenol, (1) Aysu Akça, (1) Alev Aydın \\ Kanuni Sultan Süleyman Training and Resarch Hospital, Clinic of Gynecology and Obstetrics, İstanbul, Turkey
}

\section{Abstract}

Objective: Cesarean section or operative vaginal delivery can be performed in the second stage of labor. The aim of our study was to compare cesarean deliveries performed in the second stage of labor and vacuum assisted vaginal deliveries in terms of maternal and neonatal outcomes.

Methods: Between January 2017 and January 2018, the patients who delivered by cesarean section in the second stage of labor and vacuum assisted vaginal deliveries were retrospectively evaluated. Neonatal and maternal outcome parameters were compared between the two groups.

Results: A total of 113 patients, 53 patients in the vacuum delivery group and 60 patients in the cesarean section group, were included in the study. There was no difference between the groups in terms of maternal adverse outcomes. In terms of neonatal outcomes, umbilical cord $\mathrm{pH}$ was lower in the vacuum assisted delivery group $(\mathrm{p}=0.026)$.

Conclusion: Since maternal and neonatal complications are similar, operative vaginal delivery may be considered as an alternative mode of delivery in the second stage of delivery in the appropriate patient group.

Keywords: Vacuum, cesarean section, second stage of labor

\section{INTRODUCTION}

In recent years, cesarean delivery rates have increased worldwide (1). Among the reasons for this increase are medicolegal problems, increased number of multiple pregnancies due to an increased number of pregnancies with assisted reproductive techniques, and maternal desire. In addition to planned cesarean deliveries, emergency cesarean deliveries in the second stage of labor also increased. One of the most important reasons for this increase is the hesitation of the doctors to perform vaginal deliveries with intervention in the second phase of labor due to medicolegal issues $(2,3)$.

Operative vaginal delivery is known to be associated with various maternal and neonatal complications $(4,5)$. The belief that cesarean is safer in terms of maternal and especially neonatal outcomes led to a decrease in operative vaginal deliveries. Many trials have compared forceps and vacuum-assisted delivery outcomes (6-9). Only a few studies evaluated maternal and neonatal outcomes after operative vaginal delivery and cesarean delivery.

Our study aims to compare maternal and neonatal results of cesarean deliveries performed in the second stage of birth and vacuum-assisted vaginal deliveries.

\section{METHODS}

Our study was planned as a retrospective cohort study at Kanuni Sultan Süleyman Training and Research Hospital, Department of Obstetrics and Gynecology, between January 2017 and January 2018. The study was started after approval from the Kanuni Sultan Süleyman Education and Research Hospital Ethics Committee. 
This study included live singleton pregnancies that were delivered by vacuum-assisted vaginal delivery or cesarean delivery in the second phase of labor after the 34th week of gestation. Multiple pregnancies, those with a gestational week $<34$, pregnancies with congenital fetal anomalies, and patients whose data were not fully available were excluded. Vacuum deliveries were performed with the number 5 or 6 metal bell cap.

Maternal and neonatal data and birth results were obtained from the hospital database. Maternal features were gestational week, maternal age, gravida, and parity. The main maternal outcome parameters were blood loss during labor and hemoglobin and hematocrit values after delivery. Postpartum bleeding was defined as $>500 \mathrm{~mL}$ for vacuum-assisted deliveries and $>1000$ $\mathrm{mL}$ for cesarean section. Other maternal results were lacerations (vaginal, cervical, perineal), ureteric damage, and hysterectomy.

Primary endpoints for newborns were birth weight, APGAR score at 1 st and $5^{\text {th }}$ minutes, arterial cord blood $\mathrm{pH}<7.05$, and neonatal intensive care unit requirement.

Short-term outcome parameters of newborns and mothers after vacuum-assisted vaginal delivery were compared with outcome parameters of newborns and mothers after cesarean section at the second phase of labor.

\section{Statistical Analysis}

Statistical analyses were performed using Statistical Package for Social Sciences 20.0 (SPSS Inc.; Chicago, IL, USA) package program. Distribution of quantitative data was evaluated with the Kolmogorov-Smirnov test. Student's t-test was used for normally distributed variables and the Mann-Whitney $\mathrm{U}$ test was used for non-normally distributed variables. The chi-square test was used for the evaluation of quantitative data. A sample size calculation was performed at the G-power program with an effect size of 0.5 , $\alpha$ error of 0.05 , and power of 0.95 . The calculation showed that at least 45 patients were required for each group. Statistical significance was achieved when $\mathrm{p}<0.05$.

\section{RESULTS}

Between the study dates, there were 55 vacuum-assisted deliveries and 63 cesareans at the second phase of labor in our hospital. Two patients in the vacuum group and three patients in the cesarean group were excluded because their data can't be reached. The study included 53 patients in the vacuum assisted labor group and 60 patients in the cesarean group.

Comparison of the demographic data of the patients is listed in Table 1. No difference could be detected between the groups in maternal age, gravida, parity, gestational age, prepartum hemorrhage, and hematocrit ( $p>0.05)$.

No difference could be detected between the groups in neonatal outcomes like birth weight, hospitalization at neonatal intensive care unit, and $1^{\text {st }}$ and $5^{\text {th }}$ minute APGAR scores. Umbilical cord $\mathrm{pH}$ was significantly lower in vacuum-assisted vaginal delivery group ( $p=0.026$ ). But no difference could be detected between the two groups in newborns with fetal $\mathrm{pH}<7.05(\mathrm{p}>0.05)$ (Table 2).

No difference could be found between the groups in maternal adverse results $(p>0.05)$. Uterus rupture occurred in one patient in each group. A patient in the cesarean group had ureteral damage, and three patients in the vacuum group had perineal laceration (Table 3).

\section{DISCUSSION}

The rates of operative vaginal delivery have decreased over the years, while cesarean rates in general and during the second

Table 1. Comparison of demographic data

\begin{tabular}{|l|l|l|l|}
\hline & $\begin{array}{l}\text { Vacuum-assisted } \\
\text { vaginal delivery } \\
(\mathbf{n = 5 3 )}\end{array}$ & $\begin{array}{l}\text { Cesarean } \\
\text { delivery } \\
(\mathbf{n}=60)\end{array}$ & $\mathbf{p}$ \\
\hline Maternal age & $27.00 \pm 6.72$ & $25.76 \pm 6.47$ & $0.323^{*}$ \\
\hline Gravida & $2(1-5)$ & $2(1-4)$ & $0.324 * *$ \\
\hline Para & $1(0-4)$ & $0(0-3)$ & $0.212 * *$ \\
\hline Gestational age (week) & $39.05 \pm 1.02$ & $38.83 \pm 1.12$ & $0.275^{*}$ \\
\hline $\begin{array}{l}\text { Prepartum } \\
\text { hemoglobin (g/dL) }\end{array}$ & $12.42 \pm 1.18$ & $12.61 \pm 1.05$ & $0.375^{*}$ \\
\hline $\begin{array}{l}\text { Prepartum } \\
\text { hematocrit (\%) }\end{array}$ & $37.60 \pm 3.75$ & $38.13 \pm 3.49$ & $0.439 *$ \\
\hline *Student's t-test and **Mann-Whitney U test were used \\
\hline
\end{tabular}

Table 2. Comparison of neonatal results

\begin{tabular}{|l|l|l|l|}
\hline & $\begin{array}{l}\text { Vacuum-assisted } \\
\text { vaginal delivery } \\
(\mathbf{n}=53)\end{array}$ & $\begin{array}{l}\text { Cesarean } \\
\text { delivery }(\mathbf{n}=60)\end{array}$ & $\mathbf{p}$ \\
\hline $\begin{array}{l}\text { Newborn weight } \\
(\mathrm{g})\end{array}$ & $3378.67 \pm 393.56$ & $3316.25 \pm 366.41$ & $0.385^{*}$ \\
\hline Umbilical cord pH & $7.20 \pm 0.17$ & $7.26 \pm 0.07$ & $0.026^{*}$ \\
\hline $\begin{array}{l}\text { Admission } \\
\text { to newborn } \\
\text { intensive care unit }\end{array}$ & $3(5.7 \%)$ & $2(3.3 \%)$ & $0.548 * *$ \\
\hline $\begin{array}{l}1 \text { st minute APGAR } \\
\text { score }<5\end{array}$ & $4(7.5 \%)$ & $3(5.0 \%)$ & $0.575^{* *}$ \\
\hline $\begin{array}{l}5^{\text {th }} \text { minute APGAR } \\
\text { score }<7\end{array}$ & $2(3.8 \%)$ & $0(0 \%)$ & $0.129 * *$ \\
\hline $\begin{array}{l}\text { Fetal blood pH } \\
<7.05\end{array}$ & $2(3.8 \%)$ & $1(1.7 \%)$ & $0.487 * *$ \\
\hline *Student's t-test and **chi-square test were used & \\
\hline
\end{tabular}


phase of labor have increased (10). The results of our study showed that short term maternal and neonatal complications of vacuum-assisted vaginal delivery and cesarean section during the second phase of labor were similar.

Current literature that compare operative vaginal delivery and cesarean delivery during the second phase of labor is conflicting (11-15). A study comparing operative vaginal delivery and cesarean delivery during the second phase of labor found more short term neonatal and maternal complications with operative vaginal delivery (11). Another study reported different results; no difference could be found in maternal adverse outcomes, and even less neonatal adverse results were reported for nulliparous women who delivered with forceps assistance (13). Another study showed that intracranial trauma was more frequent in newborns who had cesarean during labor (16).

According to neonatal results, our findings showed that there was no difference in $1^{\text {st }}$ and $5^{\text {th }}$ minute APGAR scores between vacuum-assisted delivery and cesarean section during labor. In our study, although there was a statistically significant difference between umbilical cord $\mathrm{pH}$ values, no difference was found between neonates with clinically significant $\mathrm{pH}<7.05$. This result is similar to the previous study results $(11,14)$. In a previous study compared with forceps deliveries, cesarean group had more newborns with a $5^{\text {th }}$ minute APGAR score $<7$ (16). Another study also showed more newborns with $5^{\text {th }}$ minute APGAR scores $<7$ in the cesarean group compared with operative vaginal deliveries, but the difference was not statistically significant (14). A factor contributing to the low APGAR score in this study may be the type of anesthesia. APGAR score at $5^{\text {th }}$ minute, and arterial $\mathrm{pH}$ value were lower in the group which had cesarean section with general anesthesia compared with the group which had cesarean

\begin{tabular}{|l|l|l|l|}
\hline \multicolumn{4}{|l|}{ Table 3. Comparison of maternal results } \\
\hline & $\begin{array}{l}\text { Vacuum assisted } \\
\text { vaginal delivery } \\
(\mathbf{n}=53)\end{array}$ & $\begin{array}{l}\text { Cesarean } \\
\text { delivery } \\
(\mathbf{n}=60)\end{array}$ & $\mathbf{p}$ \\
\hline Blood transfusion & $3(\% 5.7)$ & $4(\% 6.7)$ & $0.825^{* *}$ \\
\hline Uterus rupture & $1(\% 1.9)$ & $1(\% 1.7)$ & $0.929 * *$ \\
\hline Hysterectomy & $1(\% 1.9)$ & $0(\% 0)$ & $0.285^{* *}$ \\
\hline Ureteral injury & $0(\% 0)$ & $1(\% 1.7)$ & $0.345^{* *}$ \\
\hline Vaginal laceration & $3(\% 5.7)$ & $0(\% 0)$ & $0.062 * *$ \\
\hline $\begin{array}{l}\text { Postpartum } \\
\text { hemorrhage }\end{array}$ & $3(\% 5.7)$ & $3(\% 5.0)$ & $0.786^{* *}$ \\
\hline $\begin{array}{l}\text { Postpartum } \\
\text { hemoglobin (g/dL) }\end{array}$ & $10.69 \pm 1.30$ & $10.91 \pm 1.31$ & $0.366^{*}$ \\
\hline $\begin{array}{l}\text { Postpartum hematocrit } \\
(\%)\end{array}$ & $32.28 \pm 4.03$ & $32.75 \pm 3.69$ & $0.522 *$ \\
\hline$*$ Student's t-test and **chi-square test were used & \\
\hline
\end{tabular}

section with spinal anesthesia (17). In our study, anesthesia was not used in vacuum-assisted deliveries. Cesarean deliveries were performed under general anesthesia. We believe that, although not routinely reported in previous trials, general anesthetic agents may affect neonatal results.

Compared with vaginal deliveries, respiratory distress was higher in cesarean deliveries. Another study showed that increased cesarean rates didn't increase short term results, but admission to a neonatal intensive care unit increased with cesarean deliveries (18). However, no difference was found in neonatal intensive care unit admissions in our study. Previous studies also demonstrated that bell caps also affected neonatal and maternal results (16). Only a metal bell was used in our study.

No difference was found between the two groups regarding short-term maternal results. However, this result differs from the literature because there was no significant difference in maternal postpartum bleeding $(11,13)$. In the literature, a significant factor that contributed to high rates of anemia in an operative vaginal delivery is episiotomy, and blood loss comparable to that in a cesarean section was reported for an episiotomy (1921). Whether vaginal, perineal, and cervical lacerations increase in forceps and vacuum-assisted deliveries is still debated (11). An episiotomy is frequently applied in operative vaginal deliveries.

The results of our study demonstrated that operative vaginal delivery is not associated with worse neonatal and maternal results compared with cesarean section during the second phase of labor. Operative vaginal delivery can still be regarded as a successful method with rare adverse neonatal outcomes when administered safely and carefully. However, the results of our study and other previous studies demonstrated that the cesarean section didn't increase the maternal complication risk significantly (22).

World Health Organization Global Survey on Maternal and Perinatal Death demonstrated that compared with spontaneous vaginal death, all other delivery methods, including operative vaginal delivery and cesarean increase risk for adverse maternal results, including death and intensive care unit admission. Blood transfusion and hysterectomy are more frequent with cesarean section compared with vacuum-assisted vaginal delivery (23).

The limitations of our study are its retrospective design and inability to obtain data about fetal head level and duration of the second phase when a decision was made for interventional delivery. The main strength of our study is the performance of vacuum-assisted deliveries and cesareans by experienced specialists. 


\section{CONCLUSION}

In conclusion, alternative vaginal delivery may be thought of as an alternative method of delivery to cesarean section in an appropriate patient group, because they have similar maternal and neonatal complications. Extensive studies with large sample sizes are required to evaluate the outcomes of delivery methods at the second phase of labor.

\section{Ethics}

Ethics Committee Approval: Ethics committee approval was received for this study from the ethics committee of Kanuni Sultan Süleyman Training and Research Hospital (2017).

Informed Consent: Informed consent is not obtained due to the retrospective nature of this study.

Peer-review: Externally and internally peer-reviewed.

\section{Authorship Contributions}

Surgical and Medical Practices: B.A.Ç., Concept: I.T.Y., Design: A.A., Data Collection or Processing: G.Ş., Analysis or Interpretation: A.A., Literature Search: B.A.Ç., Writing: İ.T.Y., B.A.Ç.

Conflict of Interest: The authors have no conflicts of interest to declare.

Financial Disclosure: The authors declared that this study has received no financial support.

\section{REFERENCES}

1. Villar J, Valladares E, Wojdyla D, Zavaleta N, Carroli G, Velazco A, et al; WHO 2005 global survey on maternal and perinatal health research group. Cesarean delivery rates and pregnancy out-comes: the 2005 WHO global survey on maternal and perinatal health in Latin America. Lancet 2006;367:1819-48.

2. Al-Kadri H, Sabr Y, Al-Saif S, Abulaimoun B, Ba'Aqeel H, Saleh A. Failed individual and sequential instrumental vaginal delivery: contributing risk factors and maternalneonatal complications. Acta Obstet Gynecol Scand 2003;82:642-8.

3. Muula SD. Ethical and Practical Consideration of Women Choosing Cesarean Section Deliveries without "Medical Indication" in Developing Countries. Croat Med J 2007;48:94-102.

4. Hendler I, Kirshenbaum M, Barg M, Kees S, Mazaki-Tovi S, Moran O, et al. Choosing between bad, worse and worst: what is the preferred mode of delivery for failure of the second stage of labor?. J Matern Fetal Neonatal Med 2017;30:1861-4.

5. Ulubay M, Öztürk M, Fidan U, Keskin U, Fıratlıgil FB, Kıncı MF,et al. Skin incision lengths in caesarean section. Cukurova Med J 2016;41:82-6.

6. Al Wattar BH, Al Wattar B, Gallos I, Pirie AM. Rotational vaginal delivery with Kielland's forceps: a systematic review and metaanalysis of effectiveness and safety outcomes. Curr Opin Obstet Gynecol 2015;27:438-44.
7. Shekhar S, Rana N, Jaswal RS. A prospective randomized study comparing maternal and fetal effects of forceps delivery and vacuum extraction. J Obstet Gynaecol India 2013;63:116-9.

8. Singh A, Rathore P. A comparative study of feto-maternal outcome in instrumental vaginal delivery. J Obstet Gynaecol India 2011;61:663-6.

9. Abenhaim HA, Morin L, Benjamin A, Kinch RA. Effect of instrument preference for operative deliveries on obstetrical and neonatal outcomes. Eur J Obstet Gynecol Reprod Biol 2007;134:164-8.

10. Koc I. Increased cesarean section rates in Turkey. Eur J Contracept Reprod Health Care 2003;8:1-10.

11. Benedetto C, Marozio L, Prandi G, Roccia A, Blefari S, Fabris C. Shortterm maternal and neonatal outcomes by mode of delivery. A casecontrolled study. Eur J Obstet Gynecol Reprod Biol 2007; 135:35-40.

12. Bailit JL, Gregory KD, Reddy UM, Gonzalez-Quintero VH, Hibbard JU, Ramirez MM, et al. Maternal and neonatal out-comes by labor onset type and gestational age. Am J Obstet Gynecol 2010;202:245-57.

13. Halscott TL, Reddy UM, Landy HJ, Ramsey PS, Iqbal SN, Huang CC, et al. Maternal and neonatal outcomes by attempted mode of operative delivery from a low station in the second stage of labor. Obstet Gynecol 2015;126:1265-72.

14. Contag SA, Clifton RG, Bloom SL, Spong CY, Varner MW, Rouse DJ, et al. Neonatal outcomes and operative vaginal delivery versus cesarean delivery. Am J Perinatol 2010;27:493-9.

15. Walsh CA, Robson M, McAuliffe FM. Mode of delivery at term and adverse neonatal outcomes. Obstet Gynecol 2013;121:122-8.

16. Werner EF, Janevic TM, Illuzzi J, Funai EF, Savitz DA, Lipkind HS. Mode of delivery in nulliparous women and neonatal intracranial injury. Obstet Gynecol 2011;118:1239-46.

17. Saygı Ai, Özdamar Ö, Gün İ, Emirkadı H, Müngen E, Akpak YK. Comparison of maternal and fetal outcomes among patients undergoing cesarean section under general and spinal anesthesia: a randomized clinical trial. Sao Paulo Med J 2015;133:227-34.

18. Offermann H, Gebauer C, Pulzer F, Bläser A, Thome U, Knüpfer M. Cesarean section increases the risk of respiratory adaptive disorders in healthy late preterm and two groups of mature newborns. Z Geburtshilfe Neonatol 2015;219:259-65.

19. Ryman P, Ahlberg M, Ekéus C. Risk factors for anal sphincter tears in vacuum-assisted delivery. Sex Reprod Healthc 2015;6:151-6.

20. Fitzpatrick M, Behan M, O'Connell PR, O'Herlihy C. Randomised clinical trial to assess anal sphincter function following forceps or vacuum assisted vaginal delivery. BJOG 2003;110:424-9.

21. Kudish B, Blackwell S, Mcneeley SG, Bujold E, Kruger M, Hendrix SL, et al. Operative vaginal delivery and midline episiotomy: a bad combination for the perineum. Am J Obstet Gynecol 2006;195:749-54.

22. Murphy DJ, Liebling RE, Verity L, Swingler R, Patel R. Early maternal and neonatal morbidity associated with operative delivery in second stage of labour: a cohort study. Lancet 2001;358:1203-7.

23. Souza JP, Gülmezoglu A, Lumbiganon P, Laopaiboon M, Carroli G, Fawole B, et al; WHO Global Survey on Maternal and Perinatal Health Research Group. Caesarean section without medical indications is associated with an increased risk of adverse short-term maternal outcomes: the 20042008 WHO Global Survey on Maternal and Perinatal Health. BMC Med 2010;8:71. 